\title{
Michela Rossi
}

Giorgio Buratti

Editors

Computational

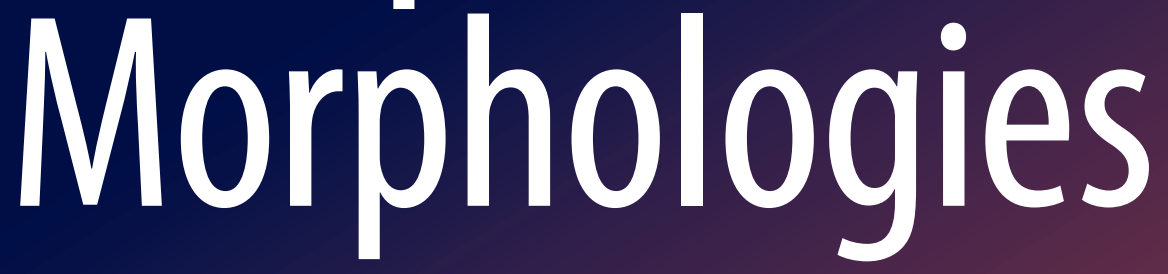

Design Rules Between Organic Models and Responsive Architecture

Springer 
Computational Morphologies 
Michela Rossi - Giorgio Buratti Editors

\section{Computational Morphologies}

Design Rules Between Organic Models and Responsive Architecture

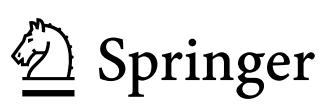




\section{Editors}

Michela Rossi

School of Design

Politecnico di Milano

Milan

Italy
Giorgio Buratti

School of Design

Politecnico di Milano

Milan

Italy

ISBN 978-3-319-60918-8

https://doi.org/10.1007/978-3-319-60919-5

ISBN 978-3-319-60919-5 (eBook)

Library of Congress Control Number: 2017946655

(C) Springer International Publishing AG 2018

This work is subject to copyright. All rights are reserved by the Publisher, whether the whole or part of the material is concerned, specifically the rights of translation, reprinting, reuse of illustrations, recitation, broadcasting, reproduction on microfilms or in any other physical way, and transmission or information storage and retrieval, electronic adaptation, computer software, or by similar or dissimilar methodology now known or hereafter developed.

The use of general descriptive names, registered names, trademarks, service marks, etc. in this publication does not imply, even in the absence of a specific statement, that such names are exempt from the relevant protective laws and regulations and therefore free for general use.

The publisher, the authors and the editors are safe to assume that the advice and information in this book are believed to be true and accurate at the date of publication. Neither the publisher nor the authors or the editors give a warranty, express or implied, with respect to the material contained herein or for any errors or omissions that may have been made. The publisher remains neutral with regard to jurisdictional claims in published maps and institutional affiliations.

Printed on acid-free paper

This Springer imprint is published by Springer Nature

The registered company is Springer International Publishing AG

The registered company address is: Gewerbestrasse 11, 6330 Cham, Switzerland 


\section{Foreword}

Founded in 1983, eCAADe-education and research in Computer Aided Architectural Design in Europe - is a nonprofit-making association of institutions and individuals with a common interest in promoting good practice and sharing information in relation to the use of computers in research and education in architecture and related professions. To fulfill this mission, eCAADe organizes an annual international conference and since 2013 additionally a Regional International Symposium. All presented research papers are published in the conference proceedings and archived in the open access platform CumInCAD (http:// www.cumincad.org), which holds papers from the worldwide sister organizations ACADIA (North America), CAADRIA (Asia), eCAADe (Europe), SIGraDI (South America), and ASCAAD (Arab region), as well as related conference series.

The eCAADe conference is hosted each year by different universities in Europe, and the conferences constitute a major event where researchers from all over the world can present the latest results of their research and exchange ideas. To help spread eCAADe's goal of fostering high-quality teaching and research in CAAD in new regions as well as in related disciplines, the eCAADe Regional International Symposium was initiated. After the first event 2013 at the University of Porto, Portugal, and the second 2014 at the Bialystok University of Technology, Poland, the third 2015 event took place at the School of Design at the Politecnico di Milano, Italy, on May 14-15.

Extending wider to other professions is also quite new to eCAADe, and we are very pleased that Prof. Michela Rossi and Prof. Maximiliano Romero from the School of Design at the Politecnico di Milano took this challenge. The scientific results shown in this publication in the fields of Design and Shape Grammar, Design and Responsivity, and Digital Heritage clearly widen the view of the eCAADe community. The presented papers show the very high quality of the Italian research, and also some typical, regional focuses that other researchers can learn from.

The eCAADe organization thanks the local organizing committee, particularly Prof. Michela Rossi and Prof. Maximiliano Romero, for their great efforts in organizing this symposium on the theme "Computational Geometries: design rules 
between nature model and responsive architecture", and for their work on this publication, perfectly summarizing the symposium results.

Joachim Kieferle

José Pinto Duarte

Current and Previous eCAADe Presidents 


\section{Preface}

\section{Geometry, Rules and Models}

The "Digital Revolution" is changing each side of our society. In the world of the Industrial Design, which involves as well the renovation of architecture, a deep transformation improved the representation, then the formal reference and eventually the design itself. Facilitating the creation of complex geometries, 3D modeling offered a new, powerful tool, which allowed designers to create easily organic or not regular forms of contemporary international trends. As every actual turning point, the change regarded not only the shape, which means formal features, but just the concept and then the approach to design, namely the design process. The synergy between the digital modeling and the use of prototyping machines can easily transform virtual models into actual objects, anticipating the change in production processes and industrials manufacturing. The production is changing as well. With the 3D printing, the innovation concerns specially the process, leading the way to further changes that on the one hand give new life back to old practices, on the other hand link together the designer and the maker. A new crafts age opens after the crisis that afflicted the industrial age. Actually the world's economic crisis stressed the instability of the global model of the "Western" industrial system, which built its wealth on the production of huge numbers of identical objects. The mass production gave the economic justification for manufacturing production lines to make broadly identical low-cost products, but the industrial model failed with the contemporary decline of consumption. Markets ask for adaptability and product's customization: Digital fabrication answers the requirement of a new economic model that brings back to craftwork. The industrial design was a consequence of the machine age that followed the Industrial Revolution, when Design and production have parted. The industry called a careful project to manage the whole production chain: the design process prior to the making. A common fate linked the industry to design, while it diverged from crafts. In fact, the artisan was able to create objects from a true-scale drawing, without any preliminary draft, because in handwork to 
make and to design refers to the same actor. Craftsmen just made objects, machines only produce them.

The dichotomy between the creative and the manufacturing phase, which features the industrial process, relegates the contribution of design in the drafting process. The relationship between thinking and making, originally intertwined in the action of the crafts's hand, evolved in design: The drawing played its connection role from making to thinking. It became a technical language instead of being just an active tool in creative process. Today, the integration of parametric generative software with digital prototyping in 3D printing allows the low-cost manufacturing of special pieces from the same code-model and it gets the concept of a single piece married with serial production and it puts again basic design rules at the beginning of the making process. On the other hand, it opens the way for a new type of designer-craftsperson.

A new Industrial Revolution is following this new relationship between design and making, that is new and old at the same time. To manage the transformation of tools without get rid of all the heritage of design culture, we need to re-discover the root of design. It lay in Shape Grammars and in their basic rules, which refers to the growing process of living. The design process becomes the scripting of a code in order to design a product's DNA that starts a morphing process with all its possible variants. Digital technology re-discovers and applies the fundamental principles of formal structure (grammar) and manages how these principles subtend the final form. The digital code subtends the form, and designing comes into play where the first meets the latter. The design merges with the making, they are the work of same actor, they are two steps of the same work.

These developments will have far-reaching implications in design procedures and methodologies. Digital fabrication may offer new opportunities to design, but it needs the development of a different approach in making process. Starting from these awareness, the eCAADe's Regional Workshop in Milan focused on the use of digital technologies and generative software in the design of innovative textures and surface patterns, particularly those which offer high performance to the areas of industrial design, fashion and architecture. The programme involved design and experimentation by the use of algorithmic design and digital fabrication tools, cognizant of ancient principles on the one hand, yet fully aware of innovations in new technologies on the other.

The first aim of the meeting, hosted in one of the biggest design schools in the word, was to focus participants on changes in design and in fabrication, which concern the scholars' attention to the whole process and its transformation through the digital management with the representation of their closed or interlaced systems, as they were organic systems. The second aim was to promote a comparison among schools from different countries and in between Italian schools, which arrived late to digital applications and are conditioned by important architectural heritage that conditions cities developments and attracts main economic and cultural resources. At the beginning of the twentieth century, the industrialization and the consequent social changes led to the birth of design and to radical transformations in architecture. Today, the closed relationship between man and information management 
makes it possible to amend the object during its production, combining the concept of the single piece with mass production. It is possible to create objects that change gradually their shape. They adapt to different needs of customization, and/or create have responsive element that react to environmental stimulus.

The product and the architecture become changeable and mutant. In the different scales design, from objects to buildings, the morphology changes in order to fit in "real time" with the user's needs, following a set of rules that fix the relationship between changing parameters. The parametric design is a digital structure of dynamic links in between different factors: generating events (input), the project (digital actions' processing of shape), and formal representation (output). It is a way to create responsive objects and architecture that are able to react to externals stimulus.

Parametric representation includes the variable "time", and it concerns the simulation of movement in order to check the handling of responsive elements. Digital design goes over the virtual representation and improves the interaction between the designer and the whole environment. The effect of parametric design and rapid prototyping on the development of new forms of kinematic surfaces and responsive architecture is flagrant. This digital evolution is powered by a renewed relationship between man and computer, or more generally between the human being and the digital space. The key element of the innovation is the centrality of computing in the design process, such as in new products development. Computing is the intelligent soul of design.

An articulated design process subtends the representation of this complexity. It put together on parametric modeling, on kinematic simulation of models, on digital prototyping, and on the digital acquisition of experimental mock-up models.

This book gathers several contributions to the workshop: some introductory lectures and several personal researches. Speeches are organized in three parts:

The first section focuses on design models and shape grammar, up to the management of complex forms. It begins with an analysis of the organic model and the basic theory of design.

Innovative concepts derive from organic models through the use of generative design tools and digital fabrication technologies. Shell, lattice, and grid structures can underpin patterns and surface textures. The knowledge of the Nature's harmonic relationships can be traced to Pythagorean doctrine, Vitruvian principles, and later Renaissance thinkers.

In the nineteenth and twentieth centuries, the knowledge of biological systems development provided inspiration to theoreticians like Theodore Cook, D'Arcy Wentworth Thomson, Ernst Haekel, Jay Hambidge, Matila Ghyka and Keith Ctitchlow, and practitioners like Richard Buckminister Fuller and Charles-Édouard Jeanneret-Gris (better known as Le Corbusier). In contemporary times, digital technologies allow an easy access to patterns and textures, as well as knowledge of proportion and balance, at the nano-, micro- and macro-levels; such technologies offer sources of historical inspiration in the fields of the visual arts in general and industrial design and architecture in particular. In the Nature's models, the 
industrial design and the architecture find their common origin in ancient concepts of basic design.

The second part concerns the relationship between Design, Architecture, and Responsivity. The term "Responsivity" is used in relation to the changing morphologies of the architectural artifact. As early as the 1970s, visionary thinkers like Nicholas Negroponte proposed that advances in artificial intelligence and the miniaturization of components would soon give rise to buildings, capable of changes in the external and internal environment. Thanks to technological advances, today we are able to manage these changes through pre-programmed mechanism of real-time response and feedback embedded in inhabitable spaces. It is possible to consider the building as a system which adapts its behavior to information acquired about its users. Information external to the building could also be integrated into the process, so as to respond to a multitude of condition able to create new forms of experience and expression.

The third section deals with digital heritage. "Heritage" is a broad term that refers to the study of human activity not only through the recovery of remains, but also through tradition, art, and cultural evidences and narratives. "Digital heritage" is an active area of research throughout the last decade, and it is a process of research and transmission of ideas and values and a knowledge that includes the material, the intangible and the virtual.

With the advancement of technology, digital heritage projects have enhanced their capability to increase interaction and manipulation of the research object, facilitating new findings. For example, augmented reality, the integration of digital information with the user's environment in real time, seems to be of particular relevance in the fields of archaeology, architecture, art, and city planning.

Furthermore, a few recent cases demonstrate the possibilities of heritage interpretation through use of modeling generative tools. These researches indicate new frontier in study of cultural heritage, while opening up possibilities of revealing complexity levels that could not be managed only a few years ago.

That demonstrates how digital heritage interpretation can be considered as a new process and at the same time how to ensure multiplicity in understanding the past.

That focus on cultural heritage expresses a special feature of Italian schools that apply innovative technology in the development of a new approach to the management of material and immaterial values. Actually, the application of digital technology to cultural heritage is an important topic in Italy, not only concerning digital representation, augmented reality, virtual museums, and heritage conservation. It may be an useful research tool that links tradition and innovation. New technological inventions have always made it possible to investigate and improve our knowledge of the world - think of the introduction of perspective and the use of the frame as the basis for Renaissance architecture and painting or of the studies of the lens by Galileo as the basis for the telescope and microscope. These tools, made thanks to scientific research, amplify human capabilities, while increasing the capacity for investigation and analysis and thus enabling new discoveries. Similarly, the research covered in this publication can be considered as an extension of human thought, enabling the understanding of formal properties and complex 
nonlinear phenomena which cannot be managed with traditional tools. In a word where computer-assisted design accompanying the designer from the generation of the form through its digital fabrication, the integration with theoretical analysis and comprehension tools able to maintain a high level of coherence is increasingly necessary. The creation of conceptual devices able to define correct methodological procedures represents the intellectual challenge of the future for the design disciplines.

Milan, Italy 


\section{Contents}

Architectural Fabrication: Towards Eco-Digital Design to Build

Process in Architecture. ....................... 1

Paolo Cascone, Elena Ciancio, Flavio Galdi and Andrea Giglio

\section{Part I Form and Code}

On Rules and Roots: The Organic Model in Design .............. 23

Michela Rossi

Shapes of Design: Traditional Geometry, Symmetry and

Representation. . . . . . . . . . . . . . . . . . . . . . . . 39

Giuseppe Amoruso

Pattern Spaces: A Rule-Based Approach to Architectural Design. . . . . 49

Marco Hemmerling

Algorithmic Modelling of Triply Periodic Minimal Surface. . . . . . . . 55

Giorgio Buratti

Represented Models and Typological Algorithms: The Role of

Parametric Models for the Design of Product. . . . . . . . . . . . . . 63

Andrea Casale and Michele Calvano

Project Rule-Checking for Enhancing Workers Safety in Preserving

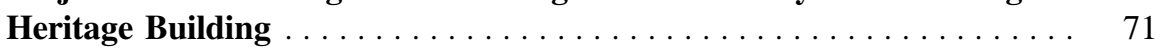

Antonio Fioravanti, Francesco Livio Rossini and Armando Trento

\section{Part II Design and Responsivity}

Architectural Templates: A Hands-On Approach to Responsive

Morphologies.

Attilio Nebuloni and Giorgio Vignati 
Architecture After the Digital Turn: Digital Fabrication Beyond the Computational Thought

Andrea Quartara

Encoding Gesture-Oriented Human Behaviour for the Development and Control of an Adaptive Building Skin

Odysseas Kontovourkis, Kristis Alexandrou and

Stavros Frangogiannopoulos

Interaction and Forming, How Industrial Design Is Changing

Maximiliano Romero

Walkacross: Space-Motion Metric for Responsive Architecture .

Paloma Gonzalez Rojas

The Management of Parameters for the Design of

Responsive Map

Cecilia Maria Bolognesi

Part III Digital Applications and Cultural Heritage

3D Modeling of an Archeological Area: The Imperial

Fora in Rome

Tommaso Empler

Augmented Visualization: New Technologies for Communicating

Architecture.

Alberto Sdegno

The Video Animation: An Innovative Way to Communicate. . . . . . . . 203

Nicola Velluzzi

Research of Nonlinear Architecture Morphology Based on Psychology

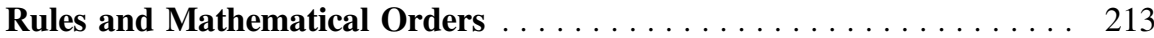

Jingting Cheng, Jianqun Lin and Weiming Zhang

Generating the Pantheon's Dome: Cultural Paradigms and Shape

Grammars

Nevena Radojevic 